\title{
La nación de las Indias en la Universidad de Bolonia (siglos XVI-XIX). Raíces medievales de la cultura hispano-americana
}

\author{
PASCUAL TAMBURRI *
}

\section{RESUMEN}

Durante los siglos modernos, existió una relación académica importante $y$ poco recordada entre Bolonia y las Indias españolas, que llevó sucesivamente a la presencia de estudiantes y maestros en Italia, a la participación de americanos y futuros americanos en el Colegio de España y

a la formación de una "nación" de juristas con el nombre de las Indias. Si bien no es posible dar cifras absolutas,

puede concluirse que este vínculo, nunca interrumpido, contribuyó a formar la personalidad cultural del Nuevo Mundo.

PALABRAS CLAVE: América. Estudiantes. Universidad. Nación. Derecho.

\section{ABSTRACT}

During the Modern centuries existed an important relationship between Bologna and the Spanish Indies, that carried to the presence of students and masters in Itaiy, to the participation of American students in the Royal Spanish College and to the constitution of the so called "nation of the Indies" in the University. Even if it is impossible to know the total numbers, we can assure that this link, that never was interrupted, contributed to the cultural personality of the New World.

KEY WORDS:

America (Spanish Western Indies). Students. University. Nation. Law.

* Área de Historia Medieval, Universidad Pública de Navarra. Doctor en Historia por la Universidad de Bolonia. El presente trabajo se redactó originalmente durante el curso 1997-1998. 


\section{INTRODUCCIÓN}

En ocasiones ha sido necesario que los historiadores recuerden a la sociedad que el término "Universidad" no hace referencia, ya en la Edad Media, a una institución o a un edificio concretos, sino a una comunidad de maestros y estudiantes. Desde el siglo XII, o incluso desde antes, Occidente ha visto su vida intelectual marcada por la existencia de una enseñanza superior, corporativamente organizada y centrada en una red transnacional de Estudios, que ha perdurado, a veces con transformaciones profundas, hasta el presente. Las «nuevas Españas» nacidas a partir del siglo xv no han sido una excepción en su entorno cultural, y los españoles de Ultramar han participado activamente, incluso como protagonistas, en la Universidad europea, antes y después de las correspondientes declaraciones de independencia ".

La relación entre las Universidades españolas de Europa y de las Indias, incluso en los momentos fundacionales, fue de intercambio: intercambio de saberes, de afanes, de esquemas de organización, de tradiciones y, sobre todo, de personas. Del mismo modo que los Colegios y Universidades en Indias acogieron desde el principio a indígenas y españoles, la red medieval de Universidades españolas tuvo muy pronto escolares venidos del otro lado del Océano ${ }^{2}$. La extensión de este sistema, ya entonces secular y depurado, a las enormes extensiones descubiertas, supuso un esfuerzo entre los más prodigiosos de nuestra historia cultural.

Esta presencia, especialmente en los siglos modernos, ha planteado muchas dificultades en su estudio, considerando las innegables peculiaridades del caso. Aunque no cabe discutir la función que los estudios universitarios tuvieron desde un principio en la configuración y evolución de lo que habrían de ser los Reinos extraeuropeos en todos los órdenes -político, administrativo, jurídico, eclesiástico y cultural, primordialmente-, la Monarquía nunca pudo destinar a esta tarea prioritaria todos los recursos que habrían sido necesarios, y los Estudios Generales y Colegios alli creados nunca bastaron. Las gentes de Indias, pues, nunca dejaron de acudir a las Universidades exteriores, españolas o extranjeras. Aquí se trata de

\footnotetext{
1 KIBRE, P., The Nations in the Mediaeval Universities. Cambridge Mass., 1948, p. IX y ss. Kagan, R., Universidad y sociedad en la España moderna. Madrid, 1981

Ballesteros-Gaibrols, M., "Dos aspectos de la influencia universitaria española en Indias", Hidaiguia. Madrid, 1995, pp. 325-345, además de las observaciones generales, siempre tenidas en cuenta, de AJo GonzÁlez de Rapariegos y SAINZ DE ZúNIGA, C.M., Historia de la Universidades his pánicas. Origenes y desarrollo desde su aparición hasta nuestros dias, I: Medievo y Renacimiento universitario. Madrid, 1957.
} 
definir el alcance del vínculo con la más antigua de las Universidades, la de Bolonia, que tradicionalmente ha sido poco valorado y plantea elementos y circunstancias novedosos.

El tipo más acabado de lo que hoy conocemos simplificadamente por "Universidad" fueron desde la Edad Media los Estudios Generales, es decir, los Estudios a los que uno de los poderes universales (en principio) había concedido la capacidad de otorgar el grado académico de doctor y, por consiguiente, la licentia ubique docendi. Esta afirmación, restringida a unos pocos lugares seleccionados, suponía una red mucho más amplia de Estudios de primeras letras y de latinidad, a modo de cursus propedéutico para seleccionar a quienes habrían de alcanzar el supremo grado académico. A su vez, los egresados de los Estudios Generales estaban destinados a constituir el nervio de todo el sistema académico, así como de la Administración civil y eclesiástica ${ }^{3}$.

España, tanto el Estado como los particulares, tuvieron en cuenta estas consideraciones al trazarlas líneas maestras de lo que habría de ser, por un lado, la Universidad en Indias y, por otro, el flujo de universitarios ya formados, originarios o no de América, de retorno hacia los nuevos territorios. Disponer de letrados, teólogos y médicos con una formación adecuada era necesario para las Indias en al menos dos sentidos. Ante todo, por las disposiciones canónicas que obligaban al clero; después, por las demandas de la Administración.

La importancia de la Universidad de Bolonia en Europa y para España a partir del siglo XVI estuvo marcada por la prohibición fijada por Felipe II de que los estudiantes españoles acudiesen a Colegios o Universidades exteriores a la Monarquía, y esto por razones religiosas. El que se ha dado en llamar bloqueo filipino, que delimita dos etapas en el gran reinado cuyo centenario se celebra, tuvo también una gran excepción: los españoles de todos los continentes podrían seguir acudiendo al gran centro italiano, en consideración, por una parte, a la tradición española en Bolonia, tan antigua como el mismo Estudio, y, por otra, a la existencia en él del más antiguo de los siete Colegios Mayores españoles, el que el barroco siglo XVII daría en llamar Almo, Real, Mayor, Colegio de San Clemente de los Españoies. Bolonia se convirtió, asi, en la única ventana desde la que los españoles pudieron asomarse legalmente, durante más de dos siglos, a la

3 RASHDALL, H., The Universities of Europe in the Middie Ages by the late Hastings Rashdall, dean of Carlisle. A new edition in three volumes edited by F.M. Powicke, Regius Professor of Modern History in the University of Oxford and A.B. Emden, Principal of St. Edmund Hall, Oxford. Oxford, 1936, vol. I, p. 1-24, en cuanto a estos conceptos fundamentales. 
cultura europea; además, se convirtió en un escaparate único de la vertiente transoceánica de España en la Universidad italiana.

Estando así las cosas, conviene preguntarse por la imagen de las Indias en Bolonia, por el flujo de estudiantes de Indias hacia Bolonia y, a la par, por el número de gentes con formación boloñesa (especialmente jurídica) que contribuyeron a vertebrar la América española. En nuestro siglo, en que tanto las antiguas Indias como España se cuestionan su presencia en Europa, no está de más examinar cuál fue la presencia en la Universidad y en el Colegio boloñeses de ambas tendencias. Lamentablemente, aunque en los últimos quince años las investigaciones sobre la historia universitaria boloñesa, e incluso sobre el Colegio, se han multiplicado, no se ha dado en enlazar con el "problema» español, tan ligado al nacimiento y defensa de un determinado concepto de España, con el «problema» de las Indias, ¿incluidas o excluidas respecto a la identidad española? Sólo el benemérito D. Marcelino Martín de Castro mostró interés por una consideración pausada del asunto, pero no pudo llevarla plenamente a cabo.

El debate, además, se plantea en torno a la existencia, única entre todas las Universidades europeas, de una «nación» de las Indias en la Universidad boloñesa moderna, lo que ha planteado cuestiones en torno a la identidad de esta institución entre el concepto universitario y el contenido moderno del término «nación», y en torno a sus posibles orígenes. Considerada objetivamente la cuestión, la Universidad nació en un contexto todavía dominado por el Imperio y el Papado, los dos poderes universales y rivales, y ellos son los que confirieron a los Estudios la vocación universal. Los particularismos, llevados a su extremo con la aparición del concepto de nación política, nacieron en todo caso después, y supusieron un cambio también en la esfera universitaria ${ }^{4}$. La «nación» era sólo una agrupación de estudiantes para obtener mutua asistencia y mayores cuotas de participación en la Universidad, especialmente en la de los juristas. Después, política e intelectualmente, existen, y han existido desde el siglo XVIII, opiniones para definir a los distintos espacios políticos hispanoamericanos (en incluso unitariamente a todo el mundo hispanoamericano), desde su pasado, como «naciones» 5 , tomando como

Evola, J., Nazionalismo, germanesimo, nazismo. Genova, 1989, pp. 44-52.

Hay que atender a las atinadas observaciones de Maiz, R., Poesía del pasado y comunidad imaginaria: los usos políticos de la Historia en el discurso del nacionalismo, en IBARRA, P., et al., lueología y nacionalismo. Vitoria, 1992, pp. 53 y ss., en cuanto a la uprecariedad científica de la investigación abocada únicamente a la búsqueda de los origenes de la nación”. Los modelos explicativos del origen de la nación (politica) han rastreado cualquier posible precedente genético de una realidad que en modo alguno corresponde a la plena Edad Media, y, sirviéndose de la 
paradigma la «nación» boloñesa que aquí nos ocupa. Desde el punto de vista contemporáneo, uno de los signos de la existencia de la "nación" política sería la presencia, influencia y personalidad de los estudiantes de origen común en las Universidades y Colegios Mayores, lo que equivaldria a la existencia de una "natio» o varias "nationes» con denominación y contenido semejantes en el mundo universitario boloñés. Cosa muy distinta es, en la Edad Moderna, el concepto universitario y su interacción con el político.

La "nación» universitaria tuvo una triple esfera de actividades: frente a sus propios miembros (asistencia, protección, representación), frente a las otras naciones (defensa de intereses comunes) y frente a la Universidad en su conjunto (que, en Bolonia, es en realidad una suma de naciones a través de las Universidades). Este modelo es el ideal, o si se quiere, el genuinamente medieval. Más adelante, la nación adquirió tal carga externa, de politica universitaria, que llegó a vaciarse por completo de contenido interno: debe pues analizarse qué tipo de nación fue la de las Indias y cómo evolucionó, para comprobar el alcance de esta teoría sobre una hipotética paleo-nación indiana evidenciada en las Universidades boloñesas. El problema se plantea en toda su fuerza por la existencia sucesiva y simultánea de una y varias nationes hispánicas en Bolonia, hecho que se ha prestado a las más variadas interpretaciones. Para René Fédou, la nación, en el sentido más amplio, es un agrupamiento organizado de personas del mismo origen geográfico, que encuentra su expresión desde la Edad Media, por una parte, entre los comerciantes (consulados y corporaciones mercantiles), por otra entre los hombres de Iglesia (los Concilios) y, finalmente, entre maestros y estudiantes en las Universidades ${ }^{6}$. En Bolonia, esto parece ya pacíficamente aceptado, la "natio" medieval de la que se conserva la documentación más antigua es la inglesa, que incluía a todos los británico (pero no a los franceses políticamente dependientes del rey de Inglaterra); la información más abundante en los mismos siglos corresponde a los alemanes ( $y$ en la nación germánica se incluyeron en principio también neerlandeses, escandinavos, bálticos y eslavos); los españoles, por su parte, poseyeron también una estructura «nacional», ciertamente original, pero de cuya génesis y evolución premoderna no se conservan más que testimonios indirectos, ya que los archivos se

ambivalencia del término, se ha llegada a proponer una identidad entre las "nationes" universitarias, en nuestro caso las de Bolonia, y nuestras modernas naciones. Cf. JafFrelot, Ch., Los modelos explicativos del origen de las naciones y del nacionalismo, en DeLANNOI, G., y TAGUIEFF, P.A., dirs., Teorias del Nacionalismo. Barcelona, 1993, pp. 203-254.

6 FÉdou, R., et al., Léxico histórico de la Edad Media. Madrid, 1986, p. 107 
han perdido ${ }^{7}$. La adscripción a ella, como se verá en las páginas que siguen, correspondió a todos los incluidos en Hispania ${ }^{8}$, como concepto y como proyecto medievales, toda la Península incluyendo Portugal y todas sus posesiones cristianas. Nunca hubo dudas en este sentido, y el nombre de «Indias» se empleó en las primeras décadas del XVII sólo para crear una nueva estructura de poder al servicio de todos los hispani, americanos o no.

Las naciones fueron sólo la más llamativa de las múltiples vías que facilitaron el acceso a los estudios boloñeses de una parte, cuantitativamente por determinar y cualitativamente en todo caso importante, de los universitarios americanos de la Edad Moderna. Junto a las naciones, y junto a la propia nación de Indias que tan poco correctamente se ha interpretado, existió un vínculo nunca negado entre otras instituciones españolas y Bolonia: superponiéndose con el anterior, el Colegio de España y el pequeño Colegio Vives. Durante y después de cada una de estas fundaciones, siempre hubo quienes acudieron a Bolonia sin otro amparo que el de sus propios medios.

Desde el punto de vista documental, las matrículas generales, fundamento de la historia de otras instituciones universitarias, no existen en el período que nos ocupa del Estudio boloñés ${ }^{9}$. Los escolares obtenían la admisión a las nationes que constituían las Universitates (italianos citra-

7 MESINI, C., "Gli spagnoli a Bologna prima della fondazione del Collegio di Egidio di Albornoz (1364-1369)", Studia Albornotiana, XII, El cardenal Albornoz y el Colegio de España, il. Bolonia, 1973, pp. 55-56. Sobre el orden (si lo hubo) en la constitución de las naciones, SoribeLLI, A., "La "nazione" nelle antiche Università italiane e straniere". Studi e memorie per la storia dell'Università di Bologna, 15, 1943, pp. 122 y ss.

8 Maravall Casesnoves, J.A., El concepto de España en la Edad Media. Madrid, 1983, pp. 17 y ss., sobre los orígenes medievales del sentimiento de comunidad hispana (mencionando expresamente Bolonia y sus circunstancias), frente a la identificación de esa realidad con un hecho nacional en sentido estricto (ibidem. pp. 80-102).

9 El mejor panorama general sobre la documentación universitaria en PAQUET, J., Les matricules universitaires (Typologie des Sources du Moyen Âge Occidental, 65), Turnhout, 1992, en especial, pp. 14 y sS. GRECI, R., "L'associazionismo degli studenti dalle origini alla fine del xIV secoIO", en BrIZZI, G.P., y PINI, A.I., Studenti e Università degli studenti a Bologna dal XII al XIX secolo, Studi e memorie per la storia dell'Università di Bologna, n.s. VII. Bologna, 1988, p. 16. MALAGOLA, C., Statuti delle Università e dei collegi dello Studio di Bologna. Bologna, 1888, o. 128, y, sobre las reglas estatutarias relativas a la inscripción de los estudiantes, DENIFLE, H., "Die Statuten der Juristen-Universität Bologna vom Jahre 1317-1347, und deren Verhältnis zur jenen Paduas, Perugias, Flcrenz", Archiv für Literatur- und kirchengeschichte des Mittelalters, 3, 1887, pp. 359 y ss. Brizz।, G.P., Matricole ed effettivi. Aspetti della presenza studentesca a Bologna fra cinque e seicento, en BrizzI-PINI, op. cit., pp. 230-233. Vid. et. RASHDALL, op. cit., vol. 3, pp. 325 y ss. KiBRE, op. cit., y, sobre el caso boloñés, Sorbelli, op. cit., pp. 91-132; Colliva, P., «Statuta nationis germanicae Universitatis Bononiae, 1292-1750", Acta Germanica. Quaderni dell'Associazione Italo-Tedesca, Bologná, 1975. 
montanos y extraitalianos ultramontanos, dentro de cada grupo de civilistas, canonistas, artistas y médicos) y sólo las nationes poseían registros de miembros. Sólo los boloñeses permanecían fuera del sistema de Universitates y nationes, y eran inscritos en un liber seu matricula specialis. Lamentablemente, faltan las matrículas de las nationes hispánicas anteriores al siglo XVII, lo que implica que toda investigación debe basarse en fuentes substitutivas. La primera opción sería la constituida por otra documentación universitaria, preferentemente administrativa; una vez más, Bolonia ha perdido casi todos sus fondos anteriores a los últimos años del siglo XIV ${ }^{10}$. Así, los estatutos de las Universitates, de las nationes y de los colegios; las actas de los rectores, de las Universitates y de las nationes, especialmente detalladas en el caso de la colación de grados: Libri secreti del Colegio de doctores civilistas (desde 1337), y Acta de los Colegios de médicos y de artistas ${ }^{11}$; la contabilidad; $y$, entre otras, finalmente, la literatura universitaria, en la que aparecen maestros y estudiantes desconocidos de otro modo ${ }^{12}$. Desde mediados del XIV, además, las propias autoridades municipales, cada vez más presentes en la vida universitaria, elaboraban cada año su lista de maestros (rotuli) ${ }^{13}$. En cualquier caso, estas fuentes o no existen para el caso de las Indias o no son útiles antes de 1750 aproximadamente. Poseemos, en cambio, una excepcional fuente heráldica y monumental a la que se hará referencia en las páginas que siguen.

Estando así las cosas, la presencia de las Indias españolas en Bolonia en los siglos XVI, XVII, XVIII y XIX, fuera de aproximaciones meramente anecdóticas o bibliográficas es mal conocida. La necesidad de profundizar en ese conocimiento viene impuesta por la importancia cualitativa y cuantitativa de la comunidad universitaria española en aquelias fechas,

10 Cencetti, G., "Inventari e regesti dei fondi più importanti conservati nel R Archivio di Stato di Bologna”, Notizie degli Archivi di Stato, 1, Roma, 1941, pp. 49-54; CenCertI, G., Gli Archivi dello Studio Bolognese, Bologna, 1933 (1938); CENCETTI, G., I precedenti storici dellarchivio notarile in Bologna, en Cencetti, G., Scritti Archivistici. Roma, 1970, pp. 300-312. Archivio di Stato di Bologna, en Guida generale degli Archivi di Stato Italiani. Roma, 1981, I, p. 579; PAQUET, op. cit., passim.

11 SorbelLI, A., Liber secretus iuris caesarei dell'Università di Bologna, I: 1378-1420. Bologna, 1938; Sorbelli, A., Liber secretus iuris caesarei dell'Università di Bologna, II: 1421-1450. Bologna, 1942; PIANA, C., Liber secretus iuris caesarei dell'Università di Bologna, III: 1451-1500. Milano, 1984. Los artistas desde 1481: Archivio di Stato di Bologna [en lo sucesivo A.S.B.]. Archivi dello Studio, a partir del n. 121. Civilistas desde 1483; A.S.B., Archivi dello Studtio, a partir del n. 26. Canonistas desde 1431 ; A.S.B., Archivi dello Studio, a partir del n. 18.

12 Plana, C. Nuovi documenti sull'Università di Bologna e sul Collegio di Spagna, I. Bolonia, 1976, pp. 109-136, por ejemplo, sobre el final del siglo XV.

13 DallaRI, U., I rotuli dei lettori legisti ed artisti dello Studio Bolognese dal 1384 al 1799, 4 vol., Bologna, 1888-1924; ZAOLI, G., «Di alcuni "rotuli» dello Studio della prima metà del secolo xv", Studi e memorie per la storia dell'Università di Bologna, 3, Bologna, 1912, pp. 193-249. 
por el crucial papel de aquellos juristas como primeros portadores del alto Derecho romano y por la consolidación de una tradición que llega, con gran vigor académico hasta el siglo xx. Ciertamente la historia de la comunidad universitaria española y de las nationes correlativas se conoce con cierto detalle después de la fundación del propio Colegio, pero ahora es preciso intentar establecer los fundamentos con los que, en el futuro, pueda comprenderse el rol del Estudio boloñés respecto a América a través de España en cinco siglos de historia.

\section{LAS MUTACIONES FINIMEDIEVALES Y EL INICIO DE LA UNIVERSIDAD MODERNA. LA «NACIÓN"DE LAS INDIAS}

En el siglo XVI culmina un proceso que, iniciado doscientos años antes, tendía a identificar los intereses corporativos de los estudiantes españoles en Bolonia con la fuerza institucional del Colegio de España, que reiteradamente demostró su capacidad de defender una posición privilegiada de sus miembros y, al mismo tiempo, de erigirse en punto de agregación de una comunidad hispánica mucho más amplia. Recientes investigaciones han demostrado la importancia de la Universidad de Bolonia como única que, fuera de los dominios de la Casa de Austria, se permitía frecuentar a los escolares peninsulares ${ }^{14}$; queda, sin embargo, por trazar la historia interna de los hispani en Bolonia, y las carreras de los egresados a su regreso a España, en la medida en que no encontrasen acomodo en la amplia Administración de las posesiones italianas o ultramarinas. Respecto a los indianos, su identificación con la comunidad española fue absoluta; su presencia y su actividad, más amplia de lo hasta ahora aceptado, es el objeto de las páginas siguientes.

Dejando para más adelante consideraciones cuantitativas, desde el punto de vista organizativo, los escolares indianos de los siglos XVI y XVII presentan tres importantes novedades respecto a sus predecesores españoles. En primer lugar, colegiales o no, quedan bajo la influencia de los Rectores del Colegio. En segundo lugar, dentro de la reorganización de las nationes de las tres Universidades principales, aparece una «nación» de Indias, a la que ya nos hemos referido, que toma como excusa la presencia de gentes de aquella proveniencia en Bolonia y sobre la que es preci-

14 LARIO, D. de, "Sobre los orígenes del burócrata moderno (El Colegio de San Clemente de Bolonia durante la impermeabilización habsburguesa, 1568-1659)", Studia Albornotiana, XLIII, Bolonia, 1980, $224 \mathrm{p}$. 
so aclarar tanto en funcionamiento como el contenido real... Por último, nace en el siglo XVI un segundo Colegio español, el de Vives, de vida breve, pobre y atormentada, destinado únicamente a los estudiantes de Alcañiz, pero abierto a todos los españoles marginalmente ${ }^{15}$.

Durante toda la Edad Moderna, de acuerdo con la tradición medieval, las Universidades boloñesas fueron tres, la de los artistas (para todas las disciplinas no jurídicas) y las dos de los juristas, ultramontanos y citramontanos, como queda dicho. Desde los albores del siglo XVI, hubo normalmente un solo Rector común a todos los juristas, y con frecuencia las tres Universidades tuvieron un único Rector, que a menudo fue español y, de éstos, normalmente el propio Rector del Colegio, no sin graves problemas y tensiones. Los Rectores contaban con el asesoramiento y control de los sindicos de los estudiantes, designados a su vez por las nationes representadas en cada Universidad ${ }^{16}$. Las nationes eran todavía la verdadera fuerza de los estudiantes, pero sin constituir ya verdaderas unidades de convivencia. Entre los ultramontanos, se multiplicó enormemente el número de naciones, por necesidades políticas y para dar cabida a las ambiciones de más estudiantes, que deseaban ser consejeros y priores, cargos prestigiosos y poco costosos. En cambio, el Rectorado de los estudiantes, sin duda más prestigioso pero ciertamente carísimo de ejercer, no se cubrió desde 1579-80, en que lo hizo Lope de Varona, Rector a la vez del Colegio de España ${ }^{17}$. Desde entonces, las Universidades fueron gobernadas por priores de las naciones elegidos por sorteo; se mantuvo la ficción de la vacante, y con esto, aunque la Universidad boloñesa medieval había muerto (con gran alivio de las autoridades locales), se evitaba extender su partida de defunción.

Desde 1576, las naciones de los juristas fueron treinta y siete, aunque se han hallado rastros intermitentes de algunas otras por desdoblamiento o simplemente en las inscripciones del Archiginnasio: Dacia, Rutenia y Livonia, Flandes, Bohemia, Polonia, Hungría, Alemania, España -con sus secuelas de Valencia, Aragón y Cataluña (más a menudo separadas), Portugal, Navarra, y las Indias al menos desde 1603-, Francia, Turonense, Biturigense, Gascuña y Auvernia, Saboya, Borgoña, Inglaterra, Provenzal, Transilvania y

\footnotetext{
15 Perez Martin, A., «El Colegio Vives», Studia Albornotiana, XXXV, El cardenal Albornoz y el Colegio de España, VI. Bolonia, 1979, pp. 160-163.

16 Pérez Martin, A., “La precedencia del Rector del Colegio de España. Su defensa frente a la Universidad de Bolonia en 1565", Studia Albornotiana, XXXV, El cardenal Albornoz y el Colegio de España, IV. Bolonia, 1979, pp. 703-705.

17 SIMEONI, L., Storia della Università di Bologna. Volume II, L'Età Moderna (1500-1888). Bologna, 1947, p. 12
} 
Malta. Además, los italianos o cismontanos: Roma, Nápoles, Marca Inferior, Marca Superior, Sicilia, Florencia y Pistoya, Pisa y Lucca, Siena y Arezzo, Cerdeña y Chipre, Spoleto, Rávenna, Venecia, Génova, Milán, Tesalónica (Emilia), Lombardía (Novara, Vercelli, Pavía, Tortona, Alejandría y Bobbio), Celestina (Asti, Alba, Ivrea, Acqui, Turín, Casale y Saluzzo), Romagna, Mantua, Piacenza y las Tres Ciudades (Brescia, Bérgamo y Verona). Los artistas, sin divisiones entre ellos, constituyeron dieciocho naciones: Lombardía, Tuscia, España, Inglaterra, Sarmatia, Hungría, lliria, Marcas, Romagna, Liguria, Sicilia, Marca Trevisana, Nápoles, Patrimonio, Roma, Grecia, Francia y Alemania (indudablemente de modo más cercano a la tradición medieval y a la realidad estudiantil del momento) ${ }^{18}$.

Regulada en los aspectos académicos, la vida de los estudiantes era muy libre, y Bolonia seguía teniendo gran atractivo por la variedad y riqueza de su oferta, intelectual y de todo tipo. La inscripción en la nación, obligatoria (pero no la elección misma de la nación), suponía la entrada en la comunidad estudiantil y la protección corporativa que esto ofrecía ${ }^{19}$. Como en la Edad Media, tanto a los efectos del Colegio como de las «naciones" que en las Universidades reunían a los españoles, era considerada Hispania "quidquid Pyraenei montibus et utroque mari clauditur» ${ }^{20}$. Si acaso, como consecuencia del Colegio y de la exclusión de los no españoles, la rigidez en la aplicación del concepto fue total, sin vacilaciones, como las existentes siglos antes, sobre algunos espacios políticos ambiguos (en la Francia meridional, por ejemplo), pero incluyendo en principio las nuevas tierras, a lo que los otros grupos presentes en el Estudio no se opusieron. Nos encontramos, en general, en un mundo universitario más formalista y anquilosado, y ciertamente con menos estudiantes con brillantes carreras profesionales, también por la competencia de los otros seis Colegios Mayores (los peninsulares). Frente a esto, en Bolonia, los españoles adoptaron una política de control del poder universitario, a la que, como hemos visto, se subordinó la creación de nuevas nationes. No parece haber, sin embargo, manera de datar con precisión el nacimiento de la «nación» que nos ocupa ${ }^{21}$.

18 SIMEONI, L., op. cit., pp. 66-67

19 SimeONi, L., op. cit., pp. 69 y ss. Un análisis aún válido, pese a lo limitado de las fuentes manejadas, de esta misma dinámica, en lo referido a los alemanes, en KNOD, G., Deutsche Studenten in Bologna (1289-1562). Biografischer Index zu den Acta Nationis Germanicae Universitatis Bononiensis. Berlin, 1899.

20 SIMEONI, L., op. cit., p. 76.

21 Pérez Martín, A., Proles Aegidiana I. Introducción. Los colegiales desde 1368 a 1500. BoIonia, 1979, pp. 22-25 [en lo sucesivo, los cuatro volúmenes de esta obra será citados respectivamente como Proles I, II, II y IV]. 
En lo que se conoce hasta ahora de documentación universitaria y de otras fuentes, es imposible dar una aproximación al número total de americanos que estudiaron en Bolonia en estos siglos. Ni siquiera sobre los españoles en general pueden aventurarse más que datos parciales, como los ciento treinta y dos teólogos que obtuvieron el doctorado entre 1500 y 1795 sobre un total de mil ciento cuarenta y nueve (aunque Bolonia atraía sobre todo futuros juristas) ${ }^{22}$. No hay ningún americano, en efecto, y ningún español, en las listas de rectores y priores artistas o médicos ${ }^{23}$.

Pero hay nuevos datos. En la segunda mitad del siglo XVI surgió en Bolonia una nueva sede para la Universidad, el edificio llamado ahora Archiginnasio. Se mantuvo en él la tradición medieval de decorar los muros con los escudos y símbolos de los rectores de las varias Universidades, con predominio de los juristas, y de los líderes y consejeros de las naciones. Pese al desorden inherente al lugar, los frescos en cuestión podrían ser una fuente única para el estudio de la presencia de indianos en Bolonia, y esto en dos sentidos: en primer lugar, por conservarse en nombre, origen y símbolos de los miembros más notables de la natio Indiarum desde el siglo XVI hasta el XVIII; en segundo, por aparecer en ellos estudiantes americanos no pertenecientes a la estructura a la que daban nombre, sino a otras nationes ${ }^{24}$. Los estudios llevados a cabo hasta el momento pecan en general de ser excesivamente descriptivos y, en cuanto al elemento indiano, resulta confundido dentro del conjunto de los españoles cuando no completamente olvidado. Este enorme edificio renacentista, incluso tras su reconstrucción, constituye pues una fuente de datos de primera magnitud para nuestro propósito. Comprobada la lamentable situación de las fuentes escritas relativas a la «nación» española y a sus hermanas de Bolonia, también durante la Edad Moderna, durante largas fases de la Universidad prenapoleónica, faltando las listas y matrículas, la única posibilidad de conocer la vida institucional de los estudiantes no italianos parte de los escudos de los priores y consejeros de las nationes ${ }^{25}$, conservados en los muros del palacio, que son el único testimonio

22 SIMEONI, L., op. cit., p. 122.

23 SIMEONI, L., op. cit., pp. 14 y sS.

24 Mondani Bortolan, G., "Stemmi e iscrizioni di studenti spagnoli neil'Archiginnasio bolognese», Studia Albornotiana, XIII, El cardenal Albornoz y el Colegio de España, III. Bolonia, 1973, pp. 637-701. Obra de mayor densidad científica fue la de SorbelLI, A., Le iscrizioni e gli stemmi dell'Archiginnasio, Bologna, 1916, de la que sin embargo sólo llegó a aparecer un primer volumen antes de que los bombardeos angloamericanos destruyesen buena parte de los escudos a los que aqui se hace referencia (PLESSI, G., "Per il ripristino dell'ornamentazione araldico-epigrafica nell'Archiginnasio", Strenna Storica Bolognese, 6. Bologna, 1956, pp. 105 y ss.).

25 SIMEONI, L., op. cit., pp. 20 y ss. 
sobre muchos momentos de la misma. Algunas de las 41 nationes de juristas ultramontanos, por ejemplo, se conocen sólo por este camino, dadas las destrucciones y pérdidas que han sufrido los archivos universitarios. Poseemos así datos de primera mano sobre los miembros más relevantes de la natio de las Indias y, al mismo tiempo, sobre algunos americanos de época moderna en una $u$ otras nationes ${ }^{26}$.

Desde 1623, una vez concluido el programa ornamental original, cada año se añadieron, hasta la llegada de las tropas revolucionarias francesas, los escudos de los rectores de las Universidades y de los priores y consejeros de las naciones, que a partir de un cierto momento carecieron de funciones efectivas, como las descritas más arriba, y ostentaron el cargo sólo a efectos honoríficos. Entre los teóricos americanos, esto es especialmente cierto, dado el virtual monopolio que, en la defensa de los intereses de todos los españoles, detentó desde bien pronto el Colegio de España. En ocasiones, la ambición de los estudiantes llevó a multiplicar el número de representantes de cada nación ante la Universidad, e incluso, parece ser, al nacimiento de nuevas naciones carentes de contenido real. De entre las naciones citadas, son ciertamente españolas la genuina natio Hispanorum y las sucesivamente creadas Cathelanorum (ésta puramente medieval), Aragonorum, Valentie et Majoricae, Portugalensium, Navarrensium y, finalmente, Indorum o Indiarum. Dada la catástrofe de 1944, y las restauraciones poco afortunadas, no sabemos si esta lista es completa, ni, dentro de ella, es seguro que identifiquemos estrictamente todos los nombres de americanos. En el elenco que sigue, por lo tanto, no puede pretenderse un análisis exhaustivo sino meramente ilustrativo del valor que tuvo. Ahora bien, esta cata en los frescos del Archiginnasio demuestra también que el nombre de la América española servía, sí, como cauce para la presencia de más representantes hispánicos en el núcleo rector del Estudio, pero éstos no eran realmente de Indias, aunque algunos podrían serlo eventualmente. Con todas las salvedades ya hechas sobre el valor de la muestra, no hay una conexión funcional entre la natio Indiarum y una hipotética comunidad boloñesa de estudiantes hispanoamericanos: éstos se diluyeron siempre entre todos los españoles, y la institución que tomó de ellos su denominación se mantuvo siempre en función de los intereses generales de esa colectividad.

A diferencia del Colegio Vives, cuyos bienes y archivos revirtieron al de San Clemente, pero cuya lista de Colegiales ha debido ser reelaborada a través de fuentes indirectas como los escudos del Archiginnasio a los que

26 SimeONI, L., op. cit., pp. 23 y ss. 
acabamos de referirnos, y de las naciones españolas, cuya documentación propia sólo perdura en parte mínima, el Colegio de España conserva un gran volumen de documentos modernos, que permiten conocer muy detalladamente a sus colegiales. No escasean entre ellos los americanos, que también están presentes, en estos siglos, entre los estudiantes menos afortunados que buscaron y encontraron al amparo del Colegio auxilio material e institucional (como porcionistas). Las normas de admisión no variaron sustancialmente en los requisitos geográficos de origen, aunque se introdujeron, en medio de graves dificultades, las pruebas de limpieza de sangre (que derivaron después a probanzas de hidalguia, y sin las que no se entiende la Universidad española moderna). En cuanto al número, y como premisa, es preciso señalar que raramente se cubrieron todas las plazas de colegial, tanto por las dilaciones de los patronos como por los intereses contrapuestos de los colegiales ya asentados, que en definitiva debían aceptar a cada nuevo aspirante. Esto, unido a la formación de verdaderas «dinastías» de colegiales, entre parientes, amigos y paisanos, en las que hubo pocos americanos, ocasiona una presencia menguada, reforzada, eso si, por los muchos peninsulares que después de su graduación en Italia pasaron a Indias ${ }^{27}$.

\section{LOS COLEGIALES AMERICANOS Y OTROS ESTUDIANTES}

Hispania, desde la Edad Media, y sin necesidad de remontarnos a S. Isidoro, era universalmente definida como quidquid Pyraenei montibus et utroque mari clauditur ${ }^{28}$, incluyendo toda la Península; todos sus habitantes cristianos eran, pues, hispani, susceptibles de pertenecer, como estudiantes, a la «nación» española en Bolonia (o a una de las "naciones" creadas y/o mantenidas para reforzar los votos españoles ante las grandes decisiones universitarias: las Indias), y, eventualmente, incluso, de recibir una beca del Colegio de España. Veremos a continuación cómo se planteó la cuestión de los españoles ultramarinos.

Puede parecer arbitrario intentar definir un elenco de estudiantes españoles en Bolonia vinculados a las Indias, en la medida en que debe incluir no sólo a los nacidos en Indias sino a todos los que tuvieron algo que ver en el proyecto histórico de una España transcontinental. La vinculación con América de algunos estudiantes en Bolonia, y específicamente colegiales,

27 Proles I, pp. 24-26.

28 SIMEONI, L., op. cit., p. 76. 
puede suponerse pero difícilmente demostrarse; así, Rodrigo de Santaella [Rodericus de Sancta Ella, colegial 388] ${ }^{29}$ y Martín García de Caspe [Martinus Gartie de Caspe, colegial 445] ${ }^{30}$, que fueron confesores de los Reyes Católicos. No se han tomado en consideración las relaciones ocasionales(viajes, conferencias), ni, por descontado, la pertenencia a la Orden de Isabel la Católica (que poco conserva de su carácter americano), ni las relaciones con la América no hispánica (Estado Unidos).

En el caso de los Colegiales del Mayor de San Clemente, la atribución a veces errónea de esta calidad, o las dudas sobre la misma, se ha explicado por la pérdida de buena parte de la documentación de los siglos XIV $y \mathrm{xV}, \mathrm{y}$ también de otros momentos, y por la suposición equivocada, pero frecuente en la Península, de que todos los españoles en Bolonia eran o habían sido bolonios. Ocasionalmente, en los siglos XVI, XVII y XVIII, el propio Colegio, ante el prestigio alcanzado por determinados personajes, aparentó creer que habían formado parte del mismo cuando evidentemente esto era falso ${ }^{3 t}$. Veamos, en todo caso, a qué volumen de información nos estamos enfrentando.

1. Juan Ginés de Sepúlveda [Joannes de Sepúlveda, colegial 670] ${ }^{32}$. Aun sin haber viajado nunca a Indias, la doctrina de este doctor boloñés sobre la tarea de España en las nuevas tierras y su polémica con el $P$. Bartolomé de las Casas marcó tres siglos de vida hispanoamericana. En la base está su formación jurídica clásica, como colegial de San Clemente entre 1515 y 1523, que le sirvió igualmente para participar con acierto y brillantez en la polémica paralela planteada sobre los títulos con los que se había realizado la incorporación de Navarra a la Corona. Fue

29 Proles I, pp. 342-343 (Archivo del Colegio de España en Bolonia [ACE], Liber Admissionum [L.A.], II, fol. 53 r. Vid. en adelante BERTRÁN RoIGÉ, P., Catálogo del Archivo del Colegio de España, Studia Albornotiana, XL, Bolonia, 1981); estuvo en Bolonia al menos desde 1467 y 1473 . Pl. NEDA, J., Proles Aegidiana, sive Catalogus illustrium virorum qui ex Sacro et Perinsigne Collegio Maior Sancti Clementis Hispanorum (...). Neapoli, 1632, pp. 14-15; DALLARI, op. cit., I, p. 87, y Beltrán de HeREdia, V., Bulario de la Universidad de Salamanca. Salamanca, 1966 y sS., III, $\mathrm{n}$. 1275, p. 194.

${ }_{30}$ Proles I, pp. 384-385, ACE, LA, II, fol. 99 r.; EubEL, C., Hierarchia Catholica Medii ef Recentioris Aevii, Monasterii, 1913, II, p. 113.

31 Proles IV, pp. 2032-2033.

32. Proles II, pp. 604-606. ACE, Acta Sodalium [AS], V. 1. LOSADA, A., "Una fuente olvidada del moderno Derecho Internacional: el "Demócrates primero", de Juan Ginés de Sepúlveda", Studia Albornotiana, XXXVII, El cardenal Albornoz y el Colegio de España,VI. Bolonia, 1979, pp. 215-236; PÉREz LuÑo, A.E., "Lá impronta boloñesa en el pensamiento de Juan Ginés de Sepúlveda", ibidem, pp. 237-259; CUART, B. y COSTAS, J., “Diego de Neila, colegial de Bolonia, canónigo de Salamanca y amigo de Juan Ginés de Sepúlveda", ibidem, pp. 261-313; NiEto Cumplido, M., "Fondos ibrarios de Juan Ginés de Sepúlveda en la Biblioteca de la Catedral de Córdoba», ibidem, pp. 743-750; Gómez C.RESPO, J., "Juan Ginés de Sepúlveda en el recuerdo", ibidem, pp. 751-751. 
presentado al Colegio como teólogo por Francisco Jiménez de Cisneros, Cardenal-Arzobispo de Toledo, y se doctoró en ambos Derechos en Bolonia el 13 de febrero de $1521^{33}$.

2. Juan Bretón y de Simancas [Johannes Breton et de Simancas, colegial $840{ }^{34}$. Tras estudiar en Salamanca, fue colegial en Bolonia entre el 5 de marzo de 1548 y el 2 de junio de $1550^{35}$, y en algunos momentos actuó como ecónomo del Colegio. Estudió Derecho Canónico, pero no consta que llegase a doctorarse. Era ya beneficiado de Simancas y canónigo deán de Córdoba, y el 5 de abril de 1561 fue nombrado Obispo de Cartagena de Indias, sede en la que permaneció hasta su muerte en $1570^{36}$.

3. Juan Bernardo Díaz de Lugo [supuesto colegial 40] ${ }^{37}$. Natural de Sevilla, Obispo de Calahorra desde 1545 hasta 1556, fue miembro del Consejo Supremo de Indias.

4. Antonio de Raya [Antonius de Raia, colegial 891$]^{38}$. Natural de Baeza (Jaén), su estancia en Bolonia consta desde 1559 hasta 1563, presentado por la diócesis de Salamanca ${ }^{39}$, en cuya Universidad había estudiado Derecho. En el curso 1561-1562 fue Rector de las dos Universidades de Derecho ${ }^{40}$, y fue lector del Decreto. Simultáneamente fue Rector del Colegio de España. Se doctoró en ambos Derechos el 24 de julio de 1563. Fue después Inquisidor en Cerdeña, en Llerena, en Toledo y en Granada ${ }^{41}$. El 6 de junio de 1594 fue elegido como Obispo del Cuzco, y permaneció en esta sede hasta su muerte el 28 de julio de $1606^{42}$.

5. Juan Antonio Díaz de Salcedo [Johannes Antonius Díaz de Salcedo, colegial 898] ${ }^{43}$. Nacido en Lantadilla (Burgos), obtuvo el grado de

\footnotetext{
33 MaRtin de CAStro, M., Españoles portugueses e iberoamericanos en Bolonia, 1. 1353-1499. Madrid, 1977, p. 72.

34 Proles Ii, p. 836.

35 ACE, L.A., III, fol. 203 r.

36 Eubel, op. cit., III, p. 154. Borrajo y Herrera, P., y Giner de los Ríos, H., El Colegio de Bolonia. Centón de noticias relativas a la fundación hispana de San Clemente. Madrid, 1880 , p. 222.

37 Proles IV, p. 2140. EuBEL, op. cit., II, p. 9. Se ha dicho que su candidatura como colegial no pudo ser aceptada por ser hijo ilegítimo.

38 Proles II, pp. 915-918.

39 Beltrán de HeRedia, op. cit., l, p. 264.

40 Malagola, C., I Rettori nell'antico Studio bolognese e nella moderna Università di Bologna. Note storiche sul Rettorato e serie dei Rettori. Bologna, 1888, p. 56. DALlaRI, op. cit., II, pp. 151152.

41 ACE, L.A., IV, fol. 27 r.

42 EUBEL, op. cit., III, p. 184.

43 Proles II, p. 928. ACE, L.A., IV, fol. 35 r.
} 
Bachiller en Filosofía en Salamanca, y el 4 de enero de 1561 fue admitido como colegial teólogo, propuesto por la iglesia de Sevilla. Permaneció en el Colegio hasta el 28 de abril de 1564, y durante aquellos años, además de alcanzar el grado de Doctor en Teología, fue Decano del Colegio teológico de doctores en Bolonia. Salió del Colegio de España para profesar como franciscano ${ }^{44}$, y dentro de la Orden fue Obispo de Cuba desde el 14 de marzo de 1580, presentado por el Rey, y de Nicaragua desde el 28 de julio de 1597, muriendo dentro de ese mismo año ${ }^{45}$.

6. Diego de León Garavito [Didacus de Leon Garavito Hispanus, prior, colegial-capellán 1030] ${ }^{46}$. Aunque recogido como tal en los repertorios al uso, no fue estrictamente Colegial en Bolonia, sino capellán, aunque español. No se conoce su lugar de origen, pero a falta de datos hay que presumir que era peninsular. Sin embargo, antes de doctorarse en Derecho Canónico el 21 de abril de 1610, fue consiliario de la Universidad por la "nación de las Indias", probablemente incluso antes de vincularse al Colegio, y casi con certeza sin tener ninguna relación con las Indias ${ }^{47}$. En esta primera aparición de las Indias entre las naciones hispánicas, parece ya evidente el carácter instrumental, al servicio de la más amplia comunidad hispánica, de su creación, por cuanto: 1) son sólo españoles los que se sirven de esta estructura para controlar mejor los votos dentro de las Universidades de los juristas, y 2) no es probable que ningún español hubiese venido todavía a Bolonia a estudiar desde fuera de Europa. Son seis los escudos conservados de este colegial, algunos de los cuales resultaron muy dañados por los bombardeos angloamericanos, y que merecerían por sí mismos un estudio heráldico que aquí no es posible incluir.

7. Juan Torres [Joannes de Torres Hispanus Alcanitiensis, Navarrensium], con cuatro escudos conocidos en la misma serie. Estudiante civilista, y lector del Digesto nuevo en 1610-1611, fue consiliario de la Universidad por la nación de las Indias en 1611 y después por Navarra y Aragón ${ }^{48}$. No consta, en cambio, que fuese Colegial de San Clemente, lo que nos hace ignorar más detalles sobre su trayectoria anterior y posterior. En todo caso,

44 Borrajo-Giner de los Rios, op. cit., p. 224. Mazzetti, S., Repertorio di tutti i Professori antichi e moderni della famosa Università e del celebre (...). Bologna, 1848, p. 319.

45 EUBEL, op. cit., III, pp. 182 y 257

46 Proles III, pp. 1158-1160. ASB, Liber Secretus Juris Pontificii [LSJP], VIb. ACE, LA, IV, fol. $215 \mathrm{r}$.

47 MONDANI, op. cit., p. 672. G. TONELLI, "Una «memoria" del primo studente venuto dalle Americhe nell'Università di Bologna", L'Archiginnasio, 60, Bologna, 1965, p. 572, y Strenna Storica Bolognese, 8, Bologna, 1958, p. 265 y ss., además de SIMEONı, L., op. cit., p. 66, con una confusa mención a su condición de "peruano".

48 Mondani, op. cit., pp. 690-691. Perez Martín, op. cit., p. 163. 
era peninsular, y sus reiterados cambios de «nación» demuestran el carácter subsidiario de todas ellas respecto a la comunidad hispánica.

8. Alfonso de Cereceda [Alphonsus de Cereçeda, colegial 1035] ${ }^{49}$. Conquense, permaneció en el Colegio de Bolonia entre su admisión como canonista, presentado por Luisa Carrillo de Albornoz, el 6 de enero de 1609 , y su graduación como doctor en 1611. Fue en realidad Doctor en ambos Derechos, y antes de ir a Bolonia había estudiado Leyes en Alcalá. Tras prestar servicios en la Administración ducal de Milán, fue juez en la Chancillería de Santo Domingo, y después (1642) pasó como Oidor a la de Charcas ${ }^{50}$. La Audiencia de Charcas representó para los bolonios en el Nuevo Mundo un papel similar, salvadas las distancias, al del Senado de Milán, punto de referencia constante durante dos siglos en Europa.

9. Francisco Néstares Marín [Franciscus Nestares Marinus, colegial 1078] ${ }^{51}$. Fue riojano (o al menos de la diócesis de Calahorra, lo que plantea particulares problemas en esta época: pero nada más sabemos de su origen). Fue colegial jurista en Bolonia entre 1624 y 1629 , y allí fue tesorero y secretario del Colegio, profesor de Derecho Civil en 1625 y se doctoró en ambos Derechos en 1626, si bien permaneció en disfrute de su beca hasta febrero de 1629. Después fue fiscal e inquisidor en Valencia y Santiago de Compostela. En 1647 fue nombrado Presidente y Visitador de la Audiencia de Charcas; en 1657 accedió al Consejo de Indias como Consejero y Visitador General, y falleció en 1660.

10. Pedro Vázquez de Velasco [Petrus Basquez de Velasco, colegial 1082] 52. Palentino, accedió al Colegio como canonista, presentado por Cuenca, el 27 de marzo de 1626, y permaneció en el Colegio hasta 1632, en que volvió a España como representante del mismo para elaborar las segundas pruebas (de limpieza de sangre, o de hidalguía) de nuevos colegiales. En Bolonia se doctoró en ambos Derechos en 1628, y permaneció hasta su marcha como profesor y colegial. Fue fiscal en la Audiencia de Guatemala desde 1637, Presidente de la Audiencia de Quito desde 1638 y de la de Charcas sucesivamente (aunque parece que no llegó a incorporarse a este último puesto) ${ }^{53}$.

11. Cristóbal de la Calancha y Valenzuela [Christoforus de la Calancha et Valensuela, colegial 1112] ${ }^{54}$. Natural de Jaén y Licenciado

\footnotetext{
Proles III, pp. 1164-1066.

ACE, LA, IV, fol. 220 r.

Proles III, pp. 1255-1258. ACE, LA, V, fol. 26 v.

Proles III, pp. 1270-1272.

ACE, LA, V, fol. $36 \mathrm{r}$.

Proles lil, pp. $1324-1325$
} 
en Derecho, fue nombrado como colegial canonista por Cuenca en 1637 y permaneció hasta 1638 (período en el cual fue consiliario del Colegio y de la correspondiente Universidad, además de profesor decretista, y en el que, como representante del Colegio, tuvo un violento incidente con un Visitador real). No consta que llegase a graduarse como Doctor, pero fue Auditor de los Galeones de la Plata, Fiscal de la Audiencia de Guatemala y Visitador Real en Méjico ${ }^{55}$.

12. Luis Ambrosio de Alarcón y Vargas [Ludovicus Ambrosius de Alarcon et Vargas, colegial 1199] ${ }^{56}$. Nació el 26 de diciembre de 1660 en Sevilla, donde es posible que se licenciase en Derecho Canónico (cosa que en todo caso hizo antes de llegar a Bolonia). Nombrado por el Obispo y el cabildo de Oviedo, permaneció en Bolonia entre 1689 y 1690 y fue consiliario y bibliotecario del Colegio de España. Después de salir del Colegio, donde no obtuvo el grado de doctor, ocupó varios cargos de responsabilidad (judiciales) en el Reino de Nápoles, pasando después a ser Alcalde de Casa y Corte en Madrid. Fue Consejero del Supremo de Indias, y en 1712 fue designado por Felipe $V$ Visitador y Comisario regio de los tribunales del Perú, puesto al que se incorporó en $1713^{57}$.

13. José de Potau y Olcina [Josephus de Potau et de Olzina, colegial $1214]^{58}$. Catalán, de Barcelona, fue admitido en el Colegio el 2 de julio de 1699 (presentado por Zaragoza) y permaneció en él hasta 1704, siendo como colegial consiliario, secretario, cronista y embajador ante Felipe $\mathrm{V}$ durante la guerra de Sucesión y Rector en 1703-1704. Era ya Doctor en Derecho por la Universidad de Barcelona al llegar a Italia, y allí obtuvo idéntico grado en Derecho Canónico. Durante la guerra ocupó diversos puesto jurídicos en la Administración y los Ejércitos borbónicos en Italia, y después fue Auditor en Sevilla y en Méjico, Alcalde de Casa y Corte y Ministro acompañante del Virrey del Perú ${ }^{59}$.

14. Alfonso Núñez de Haro Peralta [I/dephonsus Nunez de Haro Peralta, colegial 1263] ${ }^{60}$. Conquense, fue presentado por Toledo para una beca vacante de Teología el 27 de agosto de 1748 y permaneció en el Colegio de España (colegial, consiliario, historiador y Rector) hasta el 27 de octubre de 1752. En Bolonia obtuvo el grado de Doctor en Teología y

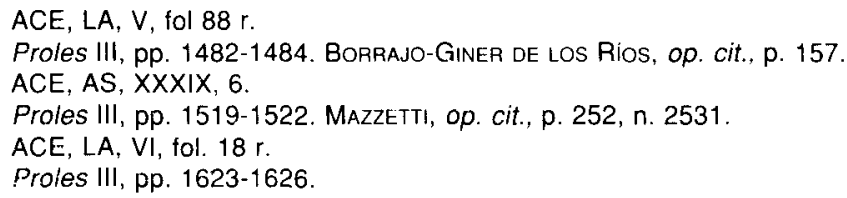


fue profesor de Teología Escolástica hasta 1754. Fue después canónigo en Segovia y en Toledo antes de pasar como Obispo a Méjico, donde estuvo desde 1772 hasta 1800 , en que murió ${ }^{61}$.

15. Jerónimo Manuel Ruedas Morales [Hieronymus Emmanuel Ruedas Morales, colegial 1273] ${ }^{62}$. Nacido en Salamanca el 17 de septiembre de 1736, obtuvo el grado de Bachiller en Leyes y Cánones antes de ir a Bolonia, probablemente en la misma Salamanca, donde fue Presidente de la Academia de Leyes y Profesor sustituto. Presentado por el Secretario de Estado y de Despacho Ricardo Wal, fue admitido como canonista en el Colegio de España el 22 de septiembre de 1756, siendo allí consiliario y secretario. Entre 1762 y 1765 fue profesor de Derecho Canónico en la Universidad de Bolonia, y abandonó Italia el 23 de mayo de 1765. Fue Fiscal real en Lima, Oidor civil en la misma Audiencia y Regente de la Cancillería de Las Charcas. Murió en Buenos Aires en 1787, alejado temporalmente de su puesto por varias imputaciones falsas que se le hicieron ${ }^{63}$.

16. Luis Miguel Urriola González Echeverz [Ludovicus Michael Urriola Gonzalez Echevertz, colegial 1290] ${ }^{64}$. Nacido en Panamá el 24 de agosto de 1748, fue presentado por el Marqués de Grimaldi, en nombre de Carlos III, para una plaza de canonista en Bolonia el 17 de febrero de 1769. Su admisión dio lugar a una interesante correspondencia entre el Colegio (los entonces Colegiales y Rector) y la Corte, por cuanto ésta, en ejercicio del alto patronato regio, pretendió que fuese admitido para una beca que originalmente pertenecía a la diócesis de Cuenca (de lo que había abundantes precedentes), y el Colegio, en respuesta, pretendió oponerse no considerando español a este americano. De esta manera, por una mal entendida aplicación estricta de los Estatutos (concebida para defender el exclusivismo de la Institución), podrían haber quedado excluidas las Indias del Colegio boloñés, como ya había sucedido con Portugal en 1659, tras la crisis de 1640. Grimaldi se impuso, e incluso las pruebas de nobleza y limpieza de sangre fueron hechas en Madrid y no en la diócesis de origen. Como colegial, fue consiliario, historiador y bibliotecario, y entre 1771 y 1775 fue profesor de Derecho Civil y Canónico en la Universidad. En 1774 y hasta 1780 en que volvió a España, autorizado por Floridablanca, fue Rector del Colegio. Por recomendación del Embajador de España en Venecia, Gálvez Esquilache, fue nombrado Oidor en Santiago de

61 ACE, LA, VI, fol 84 r.. EubeL, op. cit., VI, p. 288. MAZZETTI, op. cit., p. 225, n. 2255.

62 Proles III, pp. 1654-1656. BoRRAJO-GINER DE LOS RiOS, op. cit., pp. 185 y 237.

63 ACE, LA, VI, fol. 97 v. y ss. MAZZETTI, op. cit., p. 272, n. 2711.

64 Proles III, pp. 1786-1788. ACE, LA, VI, fol 116 r.; ACE, AS XXXVI, 10, con la correspondencia. 
Chile, puesto al que se incorporó aproximadamente en 1782-1783 (lo comunicó al Colegio en carta que llegó el 4 de febrero de 1784) ${ }^{65}$.

17. Tomás Ignacio Palomeque de Céspedes [Thomas Ignatius Palomeque de Zespedes, colegial 1301] ${ }^{66}$. Cordobés (de Fuenteovejuna), nació el 21 de diciembre de 1752, completó en Alcalá el Bachillerato en Artes y Filosofía y en Derecho Civil y Canónico. El 8 de octubre de 1776 fue presentado por el cabildo de Córdoba para una plaza de canonista; fue colegial, historiador, secretario, consiliario y bibliotecario, y permaneció en el Colegio hasta el 17 de junio de 1783. No tenía intención de abandonar entonces Bolonia de modo definitivo, pero en Barcelona supo que había sido nombrado Oidor en la nueva Audiencia de Buenos Aires, a la que se incorporó en 1784. Allí contrajo matrimonio con la hija del secretario de la Capitanía General, y fue trasladado a Las Charcas ${ }^{67}$.

18. Fernando Queipo de Llano Valdés [Ferdinandus Queypo de Liano Valdes, colegial 1310] ${ }^{68}$. Hijo de Joaquín Queipo de Llano Valdés y de María Antonia Bernaldo de Quirós, Condes de Toreno, nació en Cangas de Tineo el 29 de mayo de 1758 . En 1780 se graduó como Bachiller en Derecho Cesáreo en la Universidad de Valladolid, y en enero de 1783 fue presentado al Colegio de Bolonia por el Arzobispo de Burgos para una plaza de canonista. Fue consiliario e historiador, y entre 1787 y 1791 fue profesor de Derecho Canónico en la Universidad, pero en 1788 abandonó el Colegio. Dentro de su carrera como magistrado fue, entre sus varios destinos peninsulares y ultramarinos, Oidor en Manila, al menos de 1794 a $1795^{69}$.

19. Luis de Usoz y Río [Aloysius de Ussoz et Rio, colegial 1341] ${ }^{70}$. Natural de Cuchiraca (Audiencia de Charcas, Alto Perú, en la actual Bolivia), nació en noviembre de 1805, hijo de José Agustín Usoz y Maria Antonia del Rio ${ }^{71}$. Bachiller en Leyes por la Universidad de Alcalá, fue presentado por Fernando VII para una plaza en el Colegio de España, donde fue admitido el 15 de diciembre de $1828{ }^{72}$. Durante su estancia en el

65 BATlloRi, M., "El Colegio de España en Bolonia a finas del siglo XVlik", Studia Albornotiana, XII, El cardenal Albornoz y el Colegio de España, II. Bolonia, 1973, pp. 655-656. BORAAJO-GINER DE LOS Rios, op. cit., pp. 201 y 237. MAZZETTI, op. cit., p. 312 , n. 3052.

66 Proles III, pp. 1714-1716. ACE, LA, VI, fol 127 r.; ACE, AS, XLVIII, 1.

67 Batllori, M., op. cit., pp. 657 y 660; MAZZETTI, op. cit., p. 253, n. 2325.

68 Proles III, pp. 1732-1735. ACE, LA, VI, fol.140; ACE, AS, XLVIII, 9.

69 Batllori, M., op. cit., pp. 662-64. Borrajo-Giner de los Rios, op. cit., p. 236. MazzetTI, op. cit., p. 256, n. 2566

70 Proles IV, pp. 1788-1790. Borrajo-Giner DE los Rios, op. cit., p. 399.

3 ACE, AS, LII, 5.

72 ACE, LA, VI, fol. $178 \mathrm{~V}$. 
Colegio fue consiliario e historiador de la Institución. Se doctoró en Derecho en Bolonia, y abandonó en Colegio el 7 de octubre de 1933. Fue a continuación regente de la Cátedra de Hebreo de la Universidad de Valladolid, pero su conversión a protestantismo le hizo dedicarse al proselitismo religioso, siendo autor de numerosas obras impresas ${ }^{73}$.

20. Francisco Fleix y Soláns [colegial 1343] ${ }^{74}$. Nació en Lérida el 13 de septiembre de $1804^{75}$, fue aceptado en el Colegio de España el 19 de diciembre de 1828 , presentado por el Rey y admitido por el Rector P. Irazoqui ${ }^{76}$. Se doctoró en ambos derechos en Bolonia, y, tras abandonar el Colegio en junio de 1830, fue sucesivamente, como clérigo, canónigo de Tarragona, Maestrescuela y Vicario General en Salamanca, Capellán Real, Obispo de Puerto Rico, Obispo de La Habana y Arzobispo de Tarragona ${ }^{77}$. Permaneció en América desde su consagración en 1846 hasta su traslado en 1864 a la Península.

21. Manuel Castellanos Marín [colegial 1373] ${ }^{78}$. Nació en la ciudad de Méjico el 7 de septiembre de 1857. El 17 de abril de 1877, nombrado por el Ministro de Estado, que al mismo tiempo la atribuyó la categoría de agregado diplomático, ocupó una plaza de colegial en Bolonia, sin que se conozcan sus estudios anteriores ${ }^{79}$. Faltó del Colegio entre noviembre de 1877 y febrero de 1878 por la muerte de su padre. En enero de 1879 fue nombrado agregado diplomático en la Legación de España en Estocolmo; no regresó al Colegio, y no consta que obtuviese en Bolonia grados académicos ${ }^{80}$.

22. Juan Malcampo y Matheu [colegial 1401] ${ }^{81}$. Hijo de José Malcampo, marqués de San Rafael, nació en La Habana el 11 de mayo de 1868, y estudió Derecho en Madrid ${ }^{82}$. El 16 de febrero de 1888 fue nombrado colegial en Bolonia por el Ministro de Estado, y permaneció en el Colegio probablemente hasta el primer trimestre de 1891, aunque el estado de la documentación colegial y universitaria de esta época no permite

73 A. Palau y Dulcet, Manual del librero hispano-americano, XXIV. Barcelona, 1972, p. 342, n. 346349 a 346353. MaRTín de Castro, op. cit., pp. 80-81.

74 Proles IV, pp. 1791-1792.

75 ACE, AS, LII, 7.

76 ACE, LA, VI. fol. 179 r. y v. BorRAJO-GINER DE LOS Rios, op. cit., pp. 13 y 399.

77 De entre sus sedes episcopales, para las que fue presentado por la Reina, parece que no llegó a tomar posesión efectiva de la de San Juan, ya que en el mismo 1846 fue designado para Cuba: Eubel, op. cit., VIt, pp. 313 y 150.

76 Proles IV, p. 1817

79 ACE, AS, LIII, 14.

so Borrajo-Giner de los Rios, op. cit., p. 399.

81 Proles IV, p. 1839.

82 ACE, AS, LIII, 38. 
afirmarlo, y de hecho no se conoce con certeza el grado académico obtenido en Bolonia ni por él ni por los colegiales de su generación (como el marqués de Villamejor y su hermano mayor el conde de Romanones).

23. Rafael Comenge y Gerpe [colegial 1459] ${ }^{83}$. Natural de Manila, nació el 28 de marzo de 1894, hijo de Rafael Comenge y María Gerpe. El 12 de enero de 1921 fue nombrado por el Ministro de Estado para ocupar una plaza en Bolonia, y aceptado por el Rector M. Carrasco ${ }^{84}$. No se conoce su paradero a partir de 1922, por lo que puede presumirse que abandonó el Colegio.

24. Antonio de Luna García [colegial $1466{ }^{85}$. Formado y doctorado en Bolonia (como colegial desde 1923, en la misma generación que el Dr. Alfonso García Valdecasas) ${ }^{86}$, fue uno de los conformadores del moderno Derecho Internacional en España, y, como tal, tuvo importantes vínculos con el mundo hispánico: fue hasta 1963 Director de la Escuela de Funcionarios Internacionales, y sucesivamente Embajador de España en Bogotá y Jefe de la Asesoría Jurídica Internacional del Ministerio de Asuntos Exteriores ${ }^{87}$.

25. Luis García de Llera y Rodríguez [colegial 1472] ${ }^{88}$. Extremeño, nacido en 1905, fue colegial en Bolonia durante los cursos 1925-26 y 1926-27, al término de los cuales obtuvo el Doctorado en Derecho, especializándose en Derecho Internacional. Diplomático, sirvió en las representaciones de España en Buenos Aires y Lisboa, entre otras, antes de ser Embajador en Buenos Aires y en Santiago de Chile ${ }^{89}$.

26. Tomás Morales Pérez [colegial 1497] ${ }^{90}$. Nació en Macuto (Venezuela) el 30 de octubre de $1908^{91}$. Fue colegial en Bolonia durante 1931 y 1932, cuando obtuvo el doctorado en Derecho, tras haberse licenciado en Madrid con Premio Extraordinario. Profesó después en la Compañía de Jesús, y se doctoró también en Filosofía y en Teología ${ }^{92}$.

27. José Antonio Giménez-Arnau Gran [colegial 1498] ${ }^{93}$. Colegial en Bolonia entre 1931 y 1933, se doctoró en Derecho e ingresó después en la

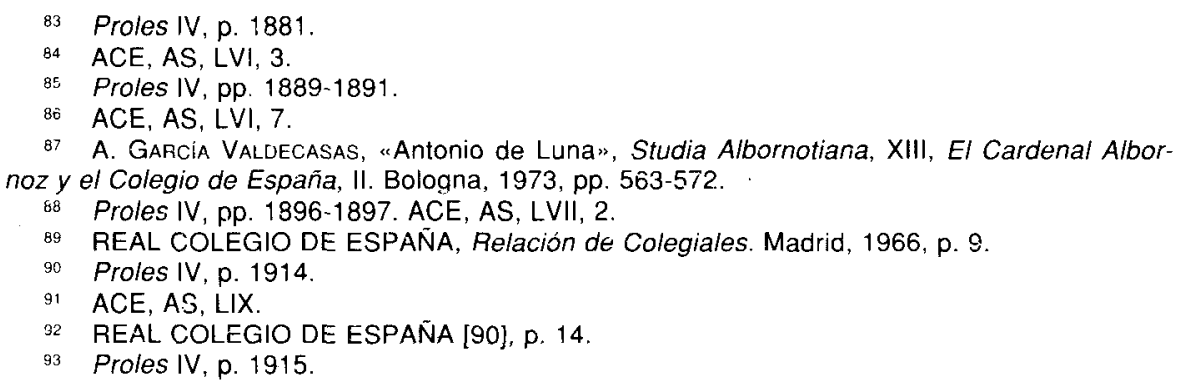


carrera diplomática. Fue Embajador de España, entre otros lugares, en Managua, Guatemala y Rio de Janeiro, con gran éxito y recibiendo numerosas condecoraciones hispanoamericanas ${ }^{94}$.

28. Santiago Sangro y Torres [colegial 1508] ${ }^{95}$. Procedente de la Universidad de Salamanca, completó sus estudios en Bolonia entre 1933 y 1935, obteniendo en esta última fecha el grado de Doctor en Derecho. Como diplomático, fue Cónsul General de España en Caracas y en Buenos Aires, además de escribir varias obras científicas o ensayísticas de contenido hispanoamericano.

29. José Beltrán de Heredia y Castaño [colegial 1516] ${ }^{96}$. Doctor en Derecho por la Universidad de Bolonia en la que fue Colegial durante los años 1934-1936, dedicó su vida profesional a la Universidad, donde alcanzó el Rectorado de la de Salamanca. Dentro del amplio movimiento de la inmediata postguerra en favor del restablecimiento de los Colegios Mayores, cuya historia está por hacer y en la que la influencia del modelo boloñés es evidente ${ }^{97}$, el Dr. Beltrán de Heredia contribuyó a introducir la inquietud hispanista, y él mismo fue Rector del Colegio Mayor Hispanoamericano "Hernán Cortés» de la Universidad de Salamanca.

Veintinueve personajes suponen, cuantitativamente, un porcentaje modesto entre aproximadamente mil quinientos expedientes en seiscientos años de Colegio ( $y$ dentro de un número desconocido de matriculas en novecientos años de Universidad). Naturalmente, la ponderación debe tener en cuenta factores cualitativos, y ahi radica la importancia de esta minoría. Los estudiantes formados en Bolonia después de los años en que el Colegio de España permaneció cerrado por efecto de las sucesivas guerras también merecen ser recordados por su vinculación con América, como los diplomáticos Raimundo Bassols Jacas ${ }^{98}$, José Luis Pardos Pérez ${ }^{99}$ y Emilio Artacho Castellano ${ }^{100}$. Especialmente digna de mención

94 REAL COLEGIO DE ESPAÑA [90], p. 13.

Proles IV, p. 1922. ACE, AS, LX.

Proles IV, pp. 1931 -32. ACE, AS, LX. REAL COLEGIO DE ESPAÑA [90], p. 15

97 Baste recordar la figura del Dr. D. Isidcro Martín, Proles IV, pp. 1925 y ss. [colegial 1511]. En realidad, los Colegios españoles de la Península y de las Indias partieron de las enseñanzas del más antiguo ejemplo, el de Bolonia, ya en su primera etapa; y al ser éste de nuevo el único existente a mediados del siglo $x x$, la dinámica era lógica, aunque evidentemente las nuevas fundaciones son sólo españolas, ya que la iniciativa no cruzó el Océano. Cf. F. Martin Hernandez, "Influencia del Colegio de San Clemente de Bolonia en los Colegios Mayores españoles", Studia Albornotiana, XII, El cardenal Albornoz y el Colegio de España, II. Bolonia, 1972, pp. 239-260.

98 Proles IV. p. 1939.

99 Proles IV, p. 1975.

100 Proles IV, p. 1976. 
es la iniciativa del Rector D. Evelio Verdera y Tuells ${ }^{101}$, que fundó y dirigió en Bolonia el Instituto de Derecho Comparado Ítalo-iberoamericano y fue profesor en Padua de Ordenamientos iusprivatísticos de los países de lengua española. Uno de los últimos colegiales nacidos en América, si no el último hasta ahora, es Jorge Antonio Rodríguez-Zapata y Pérez ${ }^{102}$, nacido en Montevideo en 1948, Doctor en Derecho por la Universidad de Bolonia en 1972, que posteriormente ha sido Asesor Jurídico del desaparecido Instituto de Cultura Hispánica.

\section{EL LEGADO DE BOLONIA}

Con el siglo XVIII, dominado por los intentos reformistas del canónigo Pérez Bayer (que afectaron por igual a todos los Colegios Mayores, incluido el boloñés), se impusieron nuevas tendencias en todas las Universidades europeas, enfrentadas con la tradición y el formalismo académicos, y también con algunas instituciones consideradas privilegiadas e ineficaces. Si los Colegios sobrevivieron, menguada su influencia, a la primera ofensiva, ésta dejó en Bolonia la huella permanente de la práctica supresión de las nationes. Desapareció así, sin ceremonias, la «nación» de las Indias, o al menos lo que de ella hubo en Bolonia: el nombre, que ya no era útil, después de dos siglos, a todos españoles, que lo emplearon cuando lo necesitaron. No por ello desaparecieron las matrículas americanas en aquella Universidad, ni desde luego las de peninsulares antes o después pasados a América. De las páginas que preceden cabe extraer algunas conclusiones que, referidas especialmente a la Edad Moderna (antes de las independencias), sirvan como balance de la vinculación específicamente académica y genéricamente cultural entre América, España y el Estudio boloñés.

En primer lugar, los estudiantes españoles e hispanoamericanos llegaron a Bolonia, por propia iniciativa, para realizar estudios jurídicos imposibles en cualquier otro lugar. Confundidos entre el conjunto de españoles, como ellos, se distinguieron por participar en la vanguardia del movimiento asociativo que, con la constitución de "naciones" universitarias, dio a los escolares el control del Estudio, y a la "natio" española (con los americanos en su interior) un lugar privilegiado entre los estudiantes.

En segundo lugar, tal vez desde finales del siglo xvi, existió en Bolonia una "nación" de Indias, institución de contenido flexible, por elasticidad in-

101 Proles IV, pp. 1946 y ss.

102 Proles IV, p. 2055. 
herente a las Universidades y al concepto boloñés de Estudio. Su existencia coloca a nuestra América en aquel Estudio en un lugar de honor, pero no hubo realmente americanos constituyéndola, sino que nació para su uso político interno por la ya consolidada comunidad de estudiantes españoles. Respecto a la imagen de las Indias en el exterior, la vida de esta "nación" pone a América al mismo nivel que los otros reinos españoles que en los siglos anteriores habian tomado parte activa en la vida del Estudio. La nación aparece como una institución de contenido flexible, por elasticidad inherente a las Universidades y al concepto boloñés de Estudio, la necesidad e interés de cuyo estudio viene limitada por la falta documentación, lo que renueva el interés por la heráldica universitaria, símbolo de una comunidad no política. Conviene no olvidar que, en la sociedad tradicional occidental, todas las formas de la actividad humana (social) estaban sometidas a reglas caracterizadas por la duración. Así como es erróneo imaginar un "Estado" medieval por analogía con el Estado moderno, las asociaciones académicas, entre ellas las nationes, si bien no tuvieron un contenido unívoco, sino que fueron verdaderas comunidades de vida, no pueden ser identificadas con las naciones contemporáneas en modo alguno ${ }^{103}$. Además, en el caso de las Indias, no puede admitirse un contenido nacional de la vida comunitaria de los universitarios en la Edad Moderna, y esto por dos razones: tras el bloqueo filipino de la migratio académico fuera de la Monarquía, los americanos se integraron perfectamente, a la par de los peninsulares, en los Estudios ibéricos; en Bolonia, única Universidad no hispánica excluida, dentro y fuera del Colegio de España, vivieron siempre sin separarse de resto de españoles, sin distinguirse de ellos en nada y permitiendo que la llamada "nación" de In dias, sin una especial presencia de americanos en su interior, no fuese más que otro instrumento colectivo del poder de los españoles como tales entre los juristas boloñeses, a la par que la «nación» aragonesa o la de las Indias. Ciertamente persisten la necesidad e interés del estudio del origen de la institución (que la falta de documentación nos hace conocer sobre todo, en un momento concreto, a través de la heráldica).

En tercer lugar, ya antes de la aparición de la «nación» de Indias, la mayor parte de los americanos y futuros americanos acudía a Bolonia becados por el Colegio de España, o protegidos de los modos más diversos por él. La presencia menguante de españoles en el Estudio, unida al relativo apogeo moderno de los medios del Colegio, hizo que la afluencia de estudiantes a Italia se vinculase a él, y que algunos españoles de otros 
orígenes desempeñasen siempre importantes puestos en la Administración española de Indias. Con la crisis de ésta y la transformación ilustrada y revolucionaria de la Universidad, casi se eclipsó la tradición americana en Bolonia, que pese a todo sigue teniendo en la segunda mitad del siglo $x x$ un carácter en buena medida español.

En definitiva, la presente aproximación a los estudiantes hispanoamericanos a lo largo de la historia universitaria boloñesa no permite definir con precisión la cantidad de escolares que en cada momento ha acudido a Italia para iniciar o completar su periplo universitario, pero sí sirve, aparte de proponer el marco de futuros estudios, como aproximación a la calidad intelectual que los retornados de Bolonia aportaron entre los siglos XVI y XVIII, especialmente, a esta comunidad. Primero españoles destinados a pasar a América, son después sus hijos los que acuden a Bolonia, y siguen haciéndolo pese a los intentos totalmente ilegales, egoístas e infructuosos de algunos colegiales (no de la Universidad) de excluirlos de la fundación albornociana. Siglo de decadencia de lo hispánico, el xix implicó un retorno a la vieja dinámica de peninsulares que preparaban en Italia futuras carreras en la Administración de lo que quedaba del Imperio. En el siglo $\mathrm{xx}$, en fin, se ha visto, por una parte, la ¿definitiva? exclusión de los hispanos no ciudadanos españoles del Colegio de San Clemente ${ }^{104}, y$, por otra, la creación de flujos y dinámicas propias de los estudiantes de todos los países hispánicos hacia Bolonia: son, también ellos, continuadores de una tradición multisecular.

104 La reforma estatutaria de 1919 y el Reglamento de 1920 excluyen expresamente a los estudiantes que, aun siendo "varones, católicos, de probada buena conducta moral y social y de excelente expediente académico», no sean súbditos del actual Reino de España y no hayan terminado su carrera en España. Como en el caso de los portugueses (más evidente todavia), podría parecer una desviación del espiritu, si no de la letra, del testamento del Cardenal fundador y de los primeros Estatutos colegiales. 